IN THE RED CROSS WORLD

\title{
THE RED CROSS AND THE FREE GIFT OF BLOOD
}

Twenty-two National Red Cross, Red Crescent and Red Lion and Sun Societies participated in the 13th International Congress of the International Society of Blood Transfusion, in Washington, D.C., August 27-September 2, 1972. The Congress Chairman was Professor T. Greenwalt, Medical Director of the blood programme of the American National Red Cross.

Over 3,500 participants from 30 countries discussed the scientific, technical and organizational problems connected with operating blood transfusion services. Information was also shared on different aspects of blood donor motivation, the recruitment of donors by the Red Cross, and the importance of the free gift of blood.

Dr. Z. S. Hantchef, representing the League of Red Cross Societies, stressed the progress reported to the Congress by the Red Cross representatives of Japan, the Federal Republic of Germany and the U.S.A. "In Japan", he said, " $95 \%$ of all blood used in transfusions is provided by the Red Cross; in the Federal Republic of Germany, $65 \%$; while in the U.S.A. $50 \%$ is provided by the Red Cross and $75 \%$ of all blood donors in that country are donors to the Red Cross. These figures represent considerable gains in results of these three National Societies in the last six years."

Another indication of progress made in Red Cross blood programmes is found in the fact that today 13 National Societies have full responsibility for national blood transfusion programmes, among the 48 National Societies that operate blood banks. All National Societies help in recruiting blood donors and in encouraging the free gift of blood, in accordance with Red Cross principles. 